\title{
Peace education curriculum objectives for Malaysian higher tertiary education: A fuzzy delphi approach
}

\author{
Muhammad Ridhuan Tony Lim Abdullah ${ }^{1}$, Muhammad Pisol Mat $\mathrm{Isa}^{2}$, Nur Arfah Abdul Sabian ${ }^{3}$, and \\ Saedah Siraj $^{4}$ \\ ${ }^{1,2,3}$ Universiti Teknologi PETRONAS \\ ${ }^{4}$ University of Malaya
}

\begin{abstract}
This paper was to analyse the voice of stakeholders on key elements for peace education curriculum objectives for Malaysian higher education system as a contribution to the progressive effort on fostering interactions among multiracial community. The larger focus of the study is to develop a peace education curriculum model based on an intercultural context that can be applied at the tertiary level. The model was developed based on Tyler's Model (Tyler, 1949). The model proposed four domains which were the objectives of the curriculum, curriculum content, and implementation and evaluation. However, this paper only focuses on elements of the curriculum objectives which is also the instrumental domain for curriculum development. Fuzzy Delphi technique and Interpretive structural modelling (ISM) were employed. The findings of model consisted of 19 Objective curriculum elements. All proposed objective elements generated through literature review were accepted by the stakeholders and the four highest agreeable elements were "To create in the learner the knowledge of the concept of peace and conflict", "To nurture respect for and appreciation of differences", "To enable students to acquire a sense of belonging towards a larger society, and to empathize and relate with individuals from other groups within that society", and "To create in the learner, the knowledge of national identity". The outcome has reflected on the three important dimensions of knowledge and value. The skill dimension was ranked lower, as response to stakeholder views that the importance of knowledge and value (concept of peace, respect, sense of belonging and national identity) should be first inculcated and followed with other skills. The outcome of the study would implicate in the systematic structuring of peace building among the multi-cultural society through peace education.
\end{abstract}

\section{Introduction}

Peace education is not a new agenda; it has been promoted by the United Nations (UN) for a long time. The UN recognises the importance of this dialogue in peace building efforts, and in 2013, it passed a resolution (67/104) designating the period 2013-2022 as the International Decade for the Rapprochement of Cultures. The UN encourages member states to take advantage of this opportunity to expand their activities related to interreligious and intercultural dialogue, fostering tolerance and mutual understanding. The government can play a role in achieving peaceful coexistence by providing high-quality education. Quality education can provide children and communities a sense of hope, help to break the cycle of poverty, improve socioeconomic development and ultimately lead to peaceful relationship. There are 120 million children in the world are denied the opportunity to receive an education. 800 million adults worldwide are illiterate. Many efforts have carried out by various agencies to create world peace. The Peace Education Foundation (PEF) has been educating children and adults conflict resolution skills all around the world for the past thirty years. The Peace Education Foundation is a non-governmental organisation (NGO) with United Nations Economic and Social Council special consultative status. As a peace promoter, the United Nations (UN) declared in its resolution 53/243, under Article 1, on the definition of culture of peace: "It is not only is the absence of conflict, but also requires a positive, dynamic participatory process where dialogue is encouraged and conflicts are solved in a spirit of mutual understanding and cooperation" (Delors, 1998); with that promotion and initiative, the curriculum model has been discussed and proposed to be implemented at primary, secondary and tertiary level. The Integral Model of Peace Education, designed by Dr. Betty Reardon and the curriculum also was relevant to be taught at Masters level in Peace Education Center, Teachers College Columbia University. The main objective of the programme was to eliminate war, but it also included numerous number of peace education and life skills programmes produced by UNESCO in war-torn countries. The objective of these programmes was to promote peace as a necessary component of post-conflict recovery process. The package includes Technical Guidelines and Capacity Development training modules on policy, programme design, and curriculum development, with the goal of integrating peace and conflict prevention into all aspects of education. The package received was supported by UNESCO Addis-Ababa Office, and assisted to test curriculum in Addis- Ababa (Ethiopia) and Yaounde (Cameroon). 
Through skill development, skill application, and social competency enhancement, an effective conflict resolution programme will foster resiliency. PEF believes that these skills can be trained and modelled by elderly. The ability to become proficient in dealing with adversity increases a child's self-esteem and hence fosters resiliency. A concerted effort is being undertaken to educate and increase awareness of peacebuilding, beginning in the home and spreading to the community and beyond. Many institutions are attempting to motivate individuals to take action, to move forward, and to make a positive difference, no matter how tiny. According to previous research, violence prevention initiatives should start at a young age and last for several years (Hawkin, Von Cleve, \& Catalano, 1991; Tolan \& Guerra, 1994; Zigler, Tuassing, \& Black, 1992). PEF provides long-term violence prevention education through up to 43 lessons per curriculum, spanning prekindergarten through grade 12. Youth violence is a growing problem, and parents and educators alike are looking for methods to safeguard their children and stop it from spreading.

\section{Importance of Peace Education}

Peace education is not only promoted in countries which experiencing armed conflict but also the countries that are multicultural in nature. It aims to resolve issues with behaviour change that allow students to establish conditions at all levels, including intrapersonal, interpersonal, intergroup, national, and international. According to Olowo (2016) Peace education should address physical, emotional, intellectual and social growth of students deeply rooted in their culture and value. According to Turay and English (2008) to build culture of peace, the education system must enable the students with knowledge, skill, value, attitude, and belief. The students also need to be equipped with knowledge on how to critically analyze the root cause of the conflict and violence which occurred in their society. Olowo (2016) added that the existence of peace is due to absence of overt and structural of violence, it is originated from poverty discrimination lack access to opportunities. Peace education should follow the eight principles derived from united Nation Resolution which are Respect all life, Non-violence, Sharing, Listening to understand, Preservation of the planet, Tolerance and Solidarity, Equality of man and woman, and Democracy.

According to Demir (2011), nations such as Sweden, Germany, Canada, the United States, and the Netherlands have built peace education programmes; however, this is not the case in Malaysia, even though we have a multi-racial, multi-ethnic, and multi-religious society, where peace education is almost unprecedented. (Zulkifli, Goh, Norbaiyah, Sazili, Lotfi, Soleimani, \& Small, 2014). Other scholars, such as Shamsul and Anis Yusoff (2011), have said that the status of ethnic relations in Malaysia is concerning as a result of ethnic clashes that arose from a Malay-Chinese group fight in May 1969. Following that incident, the New Economic Policy (NEP) was implemented in 1971 to address intra and interethnic socio-economic differences in the short and long term; however, the situation of the relationship has not improved significantly, particularly among the three dominant races of Malay, Chinese, and Indian society (Azly, 2015). According to a study conducted by Afareez, Zulfadli, and Faizah (2016), there is a need to include Peace Education as a subject in the school's curriculum. Before making it a national curriculum, policymakers and other stakeholders should analyse how it should be implemented. This is necessary before any policy is adopted in the national school system, as it will affect the ability of a significant number of students to comprehend and apply their knowledge of the subject in their daily life.

To achieve this, peace education must emphasise the development of a cooperative, rather than a competing, relationship among all key stakeholders. As a result, the focus of this research will be on constructing an intergenerational peace education curriculum model based on intercultural context. Peace education is an essentially tool for sustainable society in maintaining peace and harmony; a vital aspect captured under Sustainable Resources. The study used the Tyler Model 1949 to construct a curriculum. Tyler's model is one of the most wellknown curriculum models. Ralph Tyler introduced the Tyler's Model in his classic book Basic Principles of Curriculum and Instruction in 1949. The model provided clear process of curriculum development with clear and precise objectives, which finally help the teacher the direction of teaching and what students should achieve and easy to monitor the outcome of the study. (Brady \& Kennedy, 2010). In 1990 the model was revitalised by the establishment of outcome-based education (OBE) Tyler's model which based on the concepts of behavioural objectives, content, implementation, and evaluation are based on his justification for the model around four (4) important questions: 1. What educational goals should the school strive for? (objective) 2. What educational experiences can be provided that are likely to achieve these objectives? (content), 3. What are the best ways to organise these educational experiences? (value), 4. How can we determine if these goals have been accomplished? (assessment).

\section{METHODOLOGY}

This study only focused on the voice of stakeholders on key elements for peace education curriculum objectives for Malaysian higher education system. The objective element is the most important component of the curriculum, as it assists both teachers and students in achieving learning course outcomes in order to foster peace building. Before each element presented could be selected, it took a lot of time and effort to investigate it. The task may get more complex as the association between the activities chosen must be studied in order to produce not only a helpful but also a practical guide for implementers in order to implement an effective peace-building programme. Based on the 
circumstances discussed above, Fuzzy Delphi technique (Kaufmann and Gupta, 1988)) was employed. Tyler's Model (Tyler, 1949) was used to guide the development of an intercultural Peace Education curriculum that addressed four (4) domains: objective, content, implementation, and evaluation.

Tyler's model is used since it is based on objective-centered. FDM is a popular method for generating ideas or variables related to a problem, issue, or situation. Kaufmann and Gupta (1988) introduced Fuzzy Delphi, a wellknown decision-making technique. It's based on a hybrid of fuzzy set theory and the Delphi method (Murray, Pipino, $\&$ Gigch, 1985). The Fuzzy Delphi method is an analytical decision-making process that combines fuzzy theory with the standard Delphi approach (Linstone \& Turoff, 2002). The Delphi method is a decision-making process that entails numerous rounds of questionnaire surveys to obtain expert viewpoints on a subject being studied. According to Adler and Ziglio (1996), The Delphi method is a structured process for obtaining and distilling knowledge from a group of experts using a series of questionnaires and controlled opinion responses. The Fuzzy Delphi Method is a more advanced version of the Delphi Method that assesses the distance between the expert panel's levels of consensus using triangulation statistics (Ishikawa et al., 1993). The premise that justified the development of this method derived from the concept that in new and unexplored areas, expert opinion (participants in the study) is permitted. The Fuzzy Delphi approach was carried out as follows:

a. Identifying the relevant elements. Expert were provided with a set of proposed curriculum element for each domain. Each proposed model element was presented, discussed, and clarified so that experts could make judgment on whether it should be included in the final list (Broome \& Cromer, 1991). The list of proposed curriculum elements for the model could or could not be agreed upon by experts. Experts may also make additional recommendations for elements that are deemed appropriate for the model. The amended list of elements for each domain was given to the experts individually in the form of a survey questionnaire (refer to Appendix 2, 3, and 4) so that they may vote for appropriate curriculum elements by assigning a ranking number to each construct item. The scale utilised was one (1) to seven (7), with one (1) indicating the least favourable item and seven (7) indicating the most favourable item. The scale's interpretation is as follows: $1=$ Least favourable $2=$ Slightly favourable $3=$ Moderately favourable $4=$ Favourable $5=$ Very favourable $6=$ High favourable $7=$ Most favourable.

b. Determine Linguistic scale. To address the issue of fuzziness among the experts' opinions, a linguistic scale is determined to frame the respondents' feedback. The linguistic scale, as shown in Figure 3.1, is comparable to a Likert scale with the addition of fuzzy numbers to the scale of triangular fuzzy numbers. To account for the fuzziness of the experts' perspectives, three fuzzy values were assigned to each response: minimum value $\left(\mathrm{m}_{1}\right)$, most plausible value $\left(\mathrm{m}_{2}\right)$, and maximum value $\left(\mathrm{m}_{3}\right)$

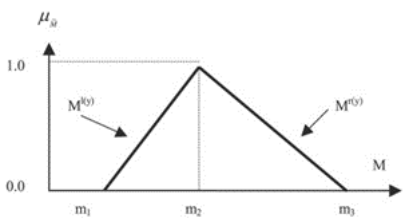

$m 1=$ Minimum value $; m 2=$ most plausible value; $m 3=$ maximum value

Figure 1. Triangular Fuzzy number 
c. Calculating Average Fuzzy values of Experts' responses. The responses of the experts to each questionnaire item, as well as the fuzzy number scales that accompanied them, were logged into an excel spreadsheet to derive the averages for $\mathrm{m}_{1}, \mathrm{~m}_{2}$, and $\mathrm{m}_{3}$.

d. Calculating Threshold value. To obtain the threshold value, 'd,' the difference between the experts' evaluation data and the average value for each item was determined using the formula below:

$$
d(\tilde{m}, \tilde{n})=\sqrt{\frac{1}{3}\left[\left(m_{1}-n_{1}\right)^{2}+\left(m_{2}-n_{2}\right)^{2}+\left(m_{3}-n_{3}\right)^{2}\right]} .
$$

The threshold value is crucial in determining the degree of expert consensus. If the threshold value is less than or equal to 0.2 , all experts are regarded to have reached a consensus, according to Cheng and Lin (2002). A minimum of $75 \%$ total group consensus is necessary; otherwise, a second round of fuzzy Delphi will be required. 'In other words, the threshold value verifies whether the expert panel is comprised of the right study participants who share a common grounding in terms of knowledge, experience, context, and commitment to contribute to the study's desired outcome.' Once the group consensus has been reached, the aggregate fuzzy evaluation is calculated by aggregating all of the fuzzy numbers for each item.

e. Deffuzification and Ranking. In the evaluation phase, the defuzzification process is the last step.

The defuzzification value for each questionnaire item was calculated using the formula below:

$$
\mathrm{A}_{\max }=1 / 4 *\left(\mathrm{a}_{1}+2 \mathrm{a}_{\mathrm{m}}+\mathrm{a}_{2}\right)
$$

Defuzzification is required in the broad application of Fuzzy Delphi to categorise the variables agreed upon by consensus of the experts by ranking of the variables. In this study, the variables were the curriculum elements of the intended intercultural peace education curriculum. Phase 2 produced a ranked list of curriculum elements as its final output. To determine the priority values for the curriculum elements, the experts' ranking numbers were summed together. Finally, the curriculum elements were prioritised based on the total ranking number. The curriculum element with the highest number on the list would be the most important.

\section{Objective Curriculum Elements}

The proposed curriculum elements were sent to the stakeholders. The most important part of a curriculum is its objectives. It constitutes the purpose of the curriculum and what should be targeted outcomes of its purpose. Then, it would make more sense in determining its content and how should the curriculum be implemented based on its objectives. To determine whether the objectives of the curriculum are achieved, the evaluation component should be included as guided in Tyler's model. Prior to determining and ranking of objective elements, the stakeholders were given the proposed elements generated through literature review.

\section{Result and Discussion}

Through Fuzzy Delphi survey exercise, the aggregated views of the panel of experts resulted in the final list of the objective elements which consisted of 19 Peace education objectives to be included in the curriculum model as shown in Table 1. A seven-point linguistic scale was used to evaluate the experts' responses to the proposed elements. The objectives were not only finalised, but they were ranked in terms of their respective level of importance. Based on participant feedback, the threshold value, 'd,' was calculated for all items in Table 1 to assess the amount of expert consensus for each item. The entries that exceeded the threshold value of 0.2 were bolded. Objective element 7 (To inculcate awareness of intercultural issues relating to ecology and the environment in the learner. $-A_{\max }=7.0 ; d=$ 0.210406 ) was the only item which exceed the value 0.2 though it was a slight over-value. However, the stakeholders agreed to retain the element since the respective value for this element obtained the accepted threshold value. The Objective element 18 (To nurture a sense of responsibility to protect ecology and environment in promoting intercultural peace $-\mathrm{A}_{\max }=6.825 ; \mathrm{d}=0.15427$ ). Their argument was the value nurture sense of responsibility to protect ecology and environment needed prior knowledge of the concept of ecology and environment on intercultural peace among the learners. The table below shown the agreed objective elements. 
Table 1: The Agreed Objective Elements for Intercultural Peace Education Curriculum

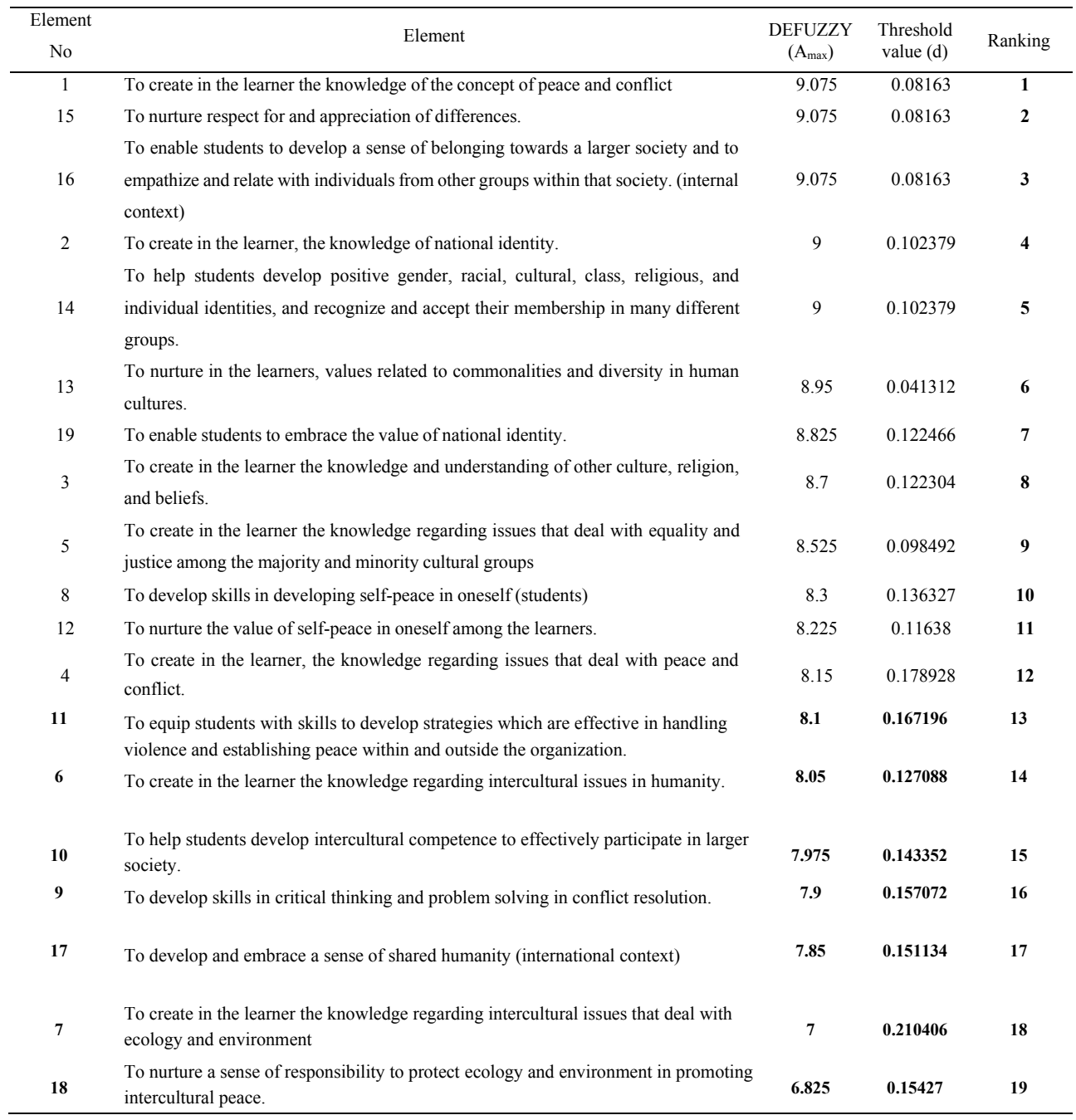

Based on Table 1 above, the top two (2) important objective elements are 'To create in the learner the knowledge of the concept of peace and conflict' $\left(A_{\max }=9.075 ; d=0.08163\right)$, 'To nurture respect for and appreciation of differences' $\left(\mathrm{A}_{\max }=9.075 ; \mathrm{d}=0.08163\right)$, these elements are from knowledge and value dimension, the stakeholders have agreed on the knowledge impartment and nurturing of respect in creating an awareness and understanding the conflict and peace. knowledge placed at the important stage in providing a sufficient information and wisdom especially at the tertiary level is critical, while nurturing value of respect and appreciation of the other cultures and beliefs are equal important, while the value such as distrust and resentment of different groups often rest on ignorance or misperception, it will plunge the society into chaotic in due course, this finding supported the previous study done by scholars such as Fountain, (1999) and Sri-Amnuay, (2011).

The second top objective element was also from the knowledge and value dimension which is 'To create in the learner, the knowledge of national identity' (Amax=9.0; $d=0.102379)$. The stakeholders agreed that the element of sense of belonging as one of the most critical element where university students should adopt, the edification of this value should be supported with comprehensive understanding of national identity of the country. Students need to share intercultural identity among multi or intercultural society to develop awareness, understanding, tolerance, accentance. and eventuallv mutual respect in peace develonment process. Different cultures normallv lead to different 
identities based on their religion and belief system. This difference of identities will potentially compromise the effort of intercultural integration in the country. The expert view on the national identity is in line with the country agenda to promulgate national cohesion and unification of multi-ethnic into one Malaysia in recent years. The advocacy on national identity was done since early days as the country experienced an ethnic conflict May 1969. The late Tun Razak was the Prime minister in his speech (22 September 1970) was saying that, the character building and individual identity must be based on national culture and upholding of Rukun Negara principle as a way forward for Malaysia to be strong, progressive and united (Tun Razak, Amanat Presiden, Jilid II)

The highest position for skill elements dimension was ranked 10 and 13 respectively. The elements are "To develop skills in developing self-peace in oneself (students)" Amax=8.3; $\mathrm{d}=0.136327$ ) and "To equip students with skills to develop strategies which are effective in handling violence and establishing peace within and outside the organization" (Amax $=8.1 ; \mathrm{d}=0.167196)$, the stakeholders was of the opinion that the skill dimension will come later than knowledge and value, the development of self-peace and strategies in handling violence within and outside the organization will be developed after the students already equipped with knowledge and value, these two skills play a central role as a compliment to knowledge and value. The importance of development of self-peace will finally establish an awareness of own needs, self-awareness, self-respect, positive self-image, then will create the needs to share with other individual's sense of justice and equality nevertheless, developing of self- peace may not be lasting, while the need to generate the skill of problem solving and create an alternative solution in coping violence and promoting peace (Fountain, S. 1999).

\section{Conclusion}

The study focussed on the stakeholders' opinion on the objective elements of peace education curriculum in Malaysian University, with the intention to promote progressive solutions towards the problems of intercultural peace. The study found that, all objective elements were accepted by stakeholders and the four highest agreeable elements are "To create in the learner the knowledge of the concept of peace and conflict", "To nurture respect for and appreciation of differences" and "To enable students to develop a sense of belonging towards a larger society and to empathize and relate with individuals from other groups within that society", and "To create in the learner, the knowledge of national identity". The outcome has reflected the three important dimension of knowledge and value and skill. The stakeholders' view on the objective element of as response to stakeholder views that the importance of knowledge and value (concept of peace, respect, sense of belonging and national identity) should be first inculcated and followed with other skills. The outcome of the study would implicate in the systematic structuring of peace building among the multi-cultural society through peace education.

\section{REFERENCES}

Adler, M., \& Ziglio, E. (1996). Gazing into the oracle: The Delphi method and its application to social policy and public health. Jessica Kingsley Publishers.

Amanat Presiden Umno 1946 - 2009, 73-75.

Afareez, Zulfadli and Faizah (2016). Exploring Educational Leaders' Perception on The Feasibility of Offering Peace Education: A Case Study, Proceedings of the International Conference on Education towards Global Peace (pp. 163-171). Nicosia Cyprus

Azly, R. (2015) One Malaysia, Under God, Bipolar: Essays on Society, Schooling, and Salvation. Petaling Jaya: Strategic Information and Research Development Centre.

Bartle, 2007 Bartle P., (2007). Participatory Management: Methods to Increase Staff Input in Organizational Decision Making: accessed available at http://cec.vcn.bc.ca/cmp/modules/pm-pm.htm.

Broome, B. J., \& Cromer, I. L. (1991). Strategic planning for tribal economic development: A culturally appropriate model for consensus building. International Journal of Conflict Management, 2(3), 217-233.

Dalkey, N. C. (1972). An Impossibility Theorem for Group Probability Functions.

Debata, B. R., Patnaik, B., Mahapatra, S. S., \& Sreekumar. (2012). An integrated approach for service quality improvement in medical tourism: an Indian perspective. International Journal of Services and Operations Management, 13(1), 119-145.

Delbecq, A. L., Van de Ven, A. H., \& Gustafson, D. H. (1975). Group techniques for program planning: A guide to nominal group and Delphi processes (pp. 83-107). Glenview, IL: Scott, Foresman.

Delors, J. (1998). Education for the twenty-first century: Issues and prospects. UNESCO. 
Demir, S. (2011). An Overview of Peace Education in Turkey: Definitions, Difficulties, and Suggestions--A Qualitative Analysis. Educational Sciences: Theory and Practice, 11(4), 1739-1745.

Fountain, S. (1999). Peace education in UNICEF. Unicef, Programme Division.

Ishikawa, A., Amagasa, M., Shiga, T., Tomizawa, G., Tatsuta, R., \& Mieno, H. (1993). The max-min Delphi method and fuzzy Delphi method via fuzzy integration. Fuzzy sets and systems, 55(3), 241-253.

Kaufmann, A., \& Gupta, M. M. (1988). Fuzzy mathematical models in engineering and management science. Elsevier Science Inc..

Linstone, H. A \& Turoff, M,(2002). The Delphi Method: techniques and applications.

Murray, T. J., Pipino, L. L., \& van Gigch, J. P. (1985). A pilot study of fuzzy set modification of Delphi. Human Systems Management, 5(1), 76-80.

Reardon, B. (1994a). Learning our way to a human future. In B. Reardon \& E. Nordland, (Eds.), Learning peace: The promise of ecological and cooperative education (pp. 21-44). Albany, NY: State University of New York Press.

Shamsul, A. B., \& Yusoff, A. Y. (2011). Managing peace in Malaysia: A case study. Ethnic Studies Paper Series, (18).

Sri-Amnuay, A. (2011). Developing a model of peace education in the undergraduate teacher training process for early childhood education at Rajabhat Universities, Thailand (Doctoral dissertation, Northumbria University).

Tolan, P., \& Guerra, N. (1994). What works in reducing adolescent violence. Boulder, CO: The Center for the Study and Prevention of Violence.

Turay, T. M., \& English, L. M. (2008). Toward a global culture of peace: A transformative model of peace education. Journal of Transformative Education, 6(4), 286-301.

Tyler, R. W. (1949). Basic Principles of Curriculum and Instruction, Chicago: University of Chicago Press.

Wang, F., \& Hannafin, M. J. (2005). Design-based research and technology-enhanced learning environments. Educational technology research and development, 53(4), 5-23.

Zigler, E., Taussig, C., \& Black, K. (1992). Early childhood intervention: a promising preventative for juvenile delinquency. American psychologist, 47(8), 997.

Zulkifli, I., Goh, Y. M., Norbaiyah, B., Sazili, A. Q., Lotfi, M., Soleimani, A. F., \& Small, A. H. (2014).

Changes in blood parameters and electroencephalogram of cattle as affected by different stunning and slaughter methods in cattle. Animal Production Science, 54(2), 187-193. 